Article

\title{
Interplay between Epigenetics, Expression of Estrogen Receptor- $\alpha$, HER2/ERBB2 and Sensitivity of Triple Negative Breast Cancer Cells to Hormonal Therapy
}

\author{
Wafaa S Ramadan ${ }^{1,2}$, Cijo George Vazhappilly ${ }^{1}$, Ekram M Saleh ${ }^{3}$, Varsha Menon ${ }^{1}$, \\ Aya M AlAzawi ${ }^{1}$, Ahmed T El-Serafi ${ }^{1,2,4}$, Wael Mansour ${ }^{3,5}$ and Raafat El-Awady ${ }^{1,3,6, *}$ \\ 1 Sharjah Institute for Medical Research, University of Sharjah, Sharjah 27272, UAE; \\ wafaa.s.ramadan@hotmail.com (W.S.R.); cijo.vazhappilly@aurak.ac.ae (C.G.V.); \\ vmenon@sharjah.ac.ae (V.M.); u00029765@sharjah.ac.ae (A.M.A.); aelserafy@sharjah.ac.ae (A.T.E.-S.) \\ 2 College of Medicine, University of Sharjah, Sharjah 27272, UAE \\ 3 Cancer Biology Department, National Cancer Institute, Cairo University, Cairo 11796, Egypt; \\ ekramsaleh@hotmail.com (E.M.S.); w.mansour@uke.de (W.M.) \\ 4 Medical Biochemistry Department, Faculty of Medicine, Suez Canal University, Ismailia 41522, Egypt \\ 5 Radiobiology and Experimental Radiooncology laboratory, Center of Oncology, University Medical Center \\ Hamburg, 20246 Hamburg, Germany \\ 6 College of Pharmacy, University of Sharjah, Sharjah 27272, UAE \\ * Correspondence: relawady@sharjah.ac.ae; Tel.: +971-0-65057409
}

Received: 17 October 2018; Accepted: 19 December 2018; Published: 21 December 2018

\begin{abstract}
Triple negative breast cancer (TNBC) cells are resistant to hormonal/targeted therapies. This study aims to investigate epigenetic differences between TNBC and other types of breast cancer and the effect of epigenetic modulation on the response of TNBC cells to hormonal therapy. Thus, we investigated (i) the expression of different epigenetic markers, (ii) the effect of epigenetic modifying agents on the expression of ER $\alpha$ and HER2/ERBB2 and (iii) the effect on the response to tamoxifen in four breast cancer cell lines with different hormonal receptor status. Our results revealed a differential expression patterns of epigenetic markers in the four breast cancer cells. In TNBC cells, histone deacetylases (HDAC) 1 and 2 were less expressed, whereas HDACs 4 and 6 were overexpressed. Interestingly, treatment with epigenetic modifiers resulted in (i) a pronounced increase in the expression of ER $\alpha$ and HER2/ERBB2 along with (ii) an increase in the sensitivity of TNBC cells to tamoxifen. Collectively, this study indicates a different epigenetic background for TNBC cells, which represses the expression of ER $\alpha$ and HER2/ERBB2. Furthermore, we provide here the rationale for the use of epigenetic modifiers to enhance the response of TNBC to hormonal therapy through upregulation of ER $\alpha$.
\end{abstract}

Keywords: triple negative breast cancer; estrogen receptor alpha; human epidermal growth factor receptor-2; epigenetics; suberoylanilide hydroxamic acid; 2'-deoxy-5-azacytidine; tamoxifen

\section{Introduction}

Breast cancer (BC) is a heterogeneous disease, which is subclassified into categories depending on the expression of estrogen and progesterone receptors and the amplification of human epidermal growth factor receptor 2 (HER2/ERBB2) [1]. Triple negative breast cancer (TNBC) is one subtype that lacks the expression of steroid hormone receptors and HER2/ERBB2 gene amplification or protein overexpression [2]. TNBC is the most heterogeneous type and accounts for $15-20 \%$ of all breast cancer cases. It has poor clinical and pathological features and considered more aggressive compared to other 
subtypes of BC such as luminal A and B [3,4]. There are only limited treatment options for TNBC, owing to the lack of suitable targeted therapeutic drugs. TNBC generally shows partial response to the available drugs because of its aggressive phenotype. Due to the lack of expression of ER $\alpha$ and HER2/ERBB2 amplification/overexpression, TNBC cells normally do not respond to hormonal therapy using drugs such as tamoxifen [5-9]. Therefore, improving the response to hormonal therapy could be a potential promising approach in the management of TNBC.

Epigenetic modifications play a significant role in carcinogenesis and in the response to chemotherapy. This is effected through the regulation of genes involved in cell replication, tumor suppression, DNA repair, and apoptosis $[10,11]$. Targeting cellular epigenetic enzymes such as DNA methyltransferases (DNMT) and histone deacetylases (HDAC), modulates the chromatin structure and thereby affects gene expression $[12,13]$. The most established DNMT inhibitor is the cytidine analogue 2'-deoxy-5-azacytidine (5-aza-dc), which is approved by the Food and Drug Administration (FDA) for the treatment of myelodysplastic syndromes. The cytotoxic activity of 5 -aza-dc is thought to be not only through its incorporation into DNA and RNA, but also by inhibiting the DNMT and targeting it to proteasomal degradation, thereby leading to DNA methylation reduction [14-16]. On the other hand, suberoylanilide hydroxamic acid (SAHA) is an HDAC inhibitor which targets class 1 and 2 HDACs. It is approved by FDA for the treatment of cutaneous T-cell lymphoma. It has a potent activity to inhibit tumor growth, induce differentiation, arrest cell cycle and promote apoptosis in variety of cancer cells, including BC [17-19].

In the present study, we investigated the effect of targeting the epigenetic modifying enzymes on the expression of ER $\alpha$ and HER2/ERBB2 and the possibility to sensitize BC cells to hormonal therapy. We report that manipulating the epigenetic machinery using 5-aza-dc and/or SAHA may provide an alternative treatment strategy to sensitize TNBC cells to hormonal therapy i.e. Tamoxifen.

\section{Results}

\subsection{Differential Expression of ER $\alpha, H E R 2 / E R B B 2, D N M T 1$ and HDACs in Breast Cancer Cells}

$E R \alpha$ and HER2/ERBB2 expressions contribute to hormonal therapy response in BC [20,21]. Here we analyzed the expression profile of these two markers in four BC cell lines (MCF7, SkBr3, BT-549 and MDA-MB-231), using western blot and immunofluorescence (Figure 1), and correlated their expression to the response to tamoxifen (TAM). Our results revealed differential expression levels of ER $\alpha$ and HER2/ERBB2 in the four cell lines (Figure 1A,B). We observed an elevated level of ER $\alpha$ in MCF7 and overexpression of HER2/ERBB2 in SkBr3 cells. This was further confirmed by immunofluorescence detection of ER $\alpha$ in MCF7/BT-549 and HER2/ERBB2 in SkBr3/BT-549 pairs (Figure 1C,D). As shown in Figure 1C, ER $\alpha$ signal was mainly observed in the nucleus in MCF7 cells, while it was absent in BT-549 cells. In addition, the signal of HER2/ERBB2 at the cell membrane of SkBr3 cells was higher compared to BT-549 cells (Figure 1D).

Differences in the expression of ER $\alpha$ and HER2/ERBB2 were translated into differential responses to hormonal therapy with TAM as measured by Sulforhodamine B (SRB) assay (Table 1; Supplementary Figure S1A). ER $\alpha$-positive MCF7 cells showed increased sensitivity to TAM with an IC50 of $6.8 \pm$ $0.24 \mu \mathrm{M}$ compared to the ER $\alpha$-negative/low BC cell lines, which showed an IC50 more than $10 \mu \mathrm{M}$. Indeed, linear regression analysis revealed a significant correlation between baseline ER $\alpha$ expression and the sensitivity to TAM ( $r=-0.9654, p=0.0346$; Table 1 and Supplementary Figure S1B). In contrast with previous findings, no correlation was found between HER2/ERBB2 expression and sensitivity to TAM in our BC models (Table 1; Supplementary Figure S1C) [22]. 
A
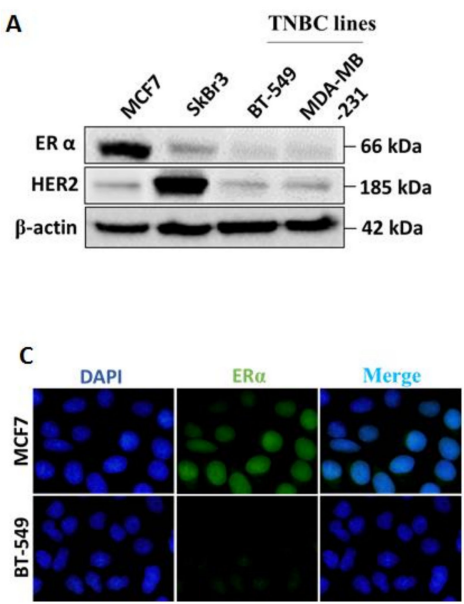

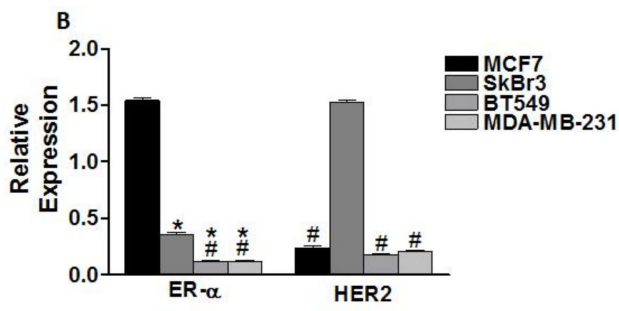

D

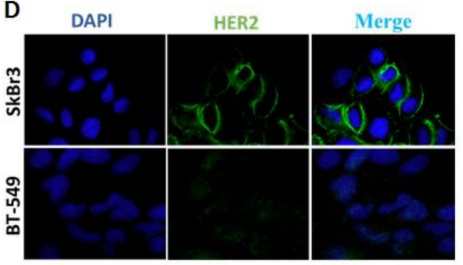

Figure 1. Differential expression of ER $\alpha$ and human epidermal growth factor receptor 2 (HER2/ERBB2) in breast cancer cells and their response to tamoxifen (TAM). (A) Western blot analysis of ER $\alpha$ and HER2/ERBB2 expression in MCF7, SkBr3, BT-549, and MDA-MB-231. Both proteins were visualized on the same blot. (B) Quantification of band intensities of the indicated proteins after normalization to $\beta$-actin. (C) Immunofluorescence detection of ER $\alpha$ in MCF7 and BT-549 (at 100 $\times$ magnification). (D) Immunofluorescence detection of HER2 in SkBr3 and BT-549 (at 100× magnification). Shown are the means \pm SEM of at least three independent experiments. ${ }^{*} p<0.05$ versus MCF7 cells and \# $p<0.05$ versus SkBr3 cells. TNBC: triple negative breast cancer.

Table 1. IC50 values of TAM, relative expression level of ER $\alpha$ and HER2/ERBB2 and their correlation to the sensitivity of the four cell lines to TAM.

\begin{tabular}{lcccc}
\hline Cell Line & MCF7 & SkBr3 & BT549 & MDA-MB-231 \\
\hline TAM IC50 $(\mu \mathrm{M})$ & $6.8 \pm 2.4$ & $12.1 \pm 0.89$ & $11.9 \pm 0.56$ & $13.8 \pm 0.1$ \\
\hline Relative ER $\alpha$ expression & $1.54 \pm 0.02$ & $0.35 \pm 0.02$ & $0.11 \pm 0.01$ & $0.11 \pm 0.01$ \\
\hline $\begin{array}{l}\text { Correlation } \\
\text { (TAM IC50 versus Relative ER } \alpha \text { expression) }\end{array}$ & & $\mathrm{r}=-0.09654, p=0.0346$ & \\
\hline Relative HER2 expression & $0.23 \pm 0.03$ & $1.53 \pm 0.02$ & $0.17 \pm 0.01$ & $0.21 \pm 0.005$ \\
\hline $\begin{array}{l}\text { Correlation } \\
\text { (TAM IC50 versus Relative HER2 expression) }\end{array}$ & $\mathrm{r}=-0.1877, p=0.8123$ & \\
\hline
\end{tabular}

Shown are the means \pm SEM of at least three independent experiments. Indicated are the $r$ values (Pearson's correlation coefficient) with the corresponding $p$ values.

Epigenetic regulations such as methylation and acetylation are main regulatory mechanisms for gene expression [10]. We next addressed the question whether the differential expression of ER $\alpha$ and HER2/ERBB2 in the indicated cell lines can be attributed to altered epigenetic regulations. To that end, the expression of different epigenetic markers (DNA methyltransferase 1, DNMT1, and histone deacetylases, HDACs) was analyzed in the four cancer cell lines (Figure 2). A differential expression of DNMT1, HDACs 1, 2, 3, 4, and 6 was observed in the examined cell lines (Figure 2A,B). Baseline levels of HDACs 1 and 2 were higher in growth-promoting receptor (ER $\alpha$ and HER2/ERBB2) positive cells (MCF7 and SkBr3), whereas HDACs 4 and 6 were higher in growth-promoting receptor negative cells (BT-549 and MDA-MB-231). Furthermore, the phosphorylation of HDACs 4, 5, and 7 was lower in $\mathrm{SkBr} 3$ cells than in the other three cell lines. Expression of DNMT1 was significantly higher in MCF7 and MDA-MB-231 cells than in the other two cell lines (Figure 2B). Linear regression analysis showed a negative correlation between the expression of growth-promoting receptors and the baseline levels of both HDAC4 $(\mathrm{r}=-0.9731, p=0.0269)$ and HDAC6 $(\mathrm{r}=-0.9711, p=0.0289)$ (Figure 2C and Table 2). However, no significant correlation was observed between the expression of other epigenetic markers 
(DNMT1, HDACs 1, 2, and 3) and the level of ER $\alpha$ and HER2/ERBB2 in the four cell lines (Figure 2C and Table 2).

A

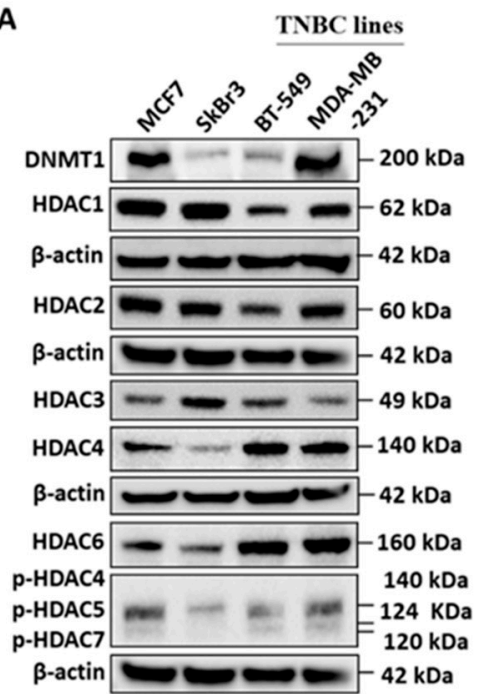

B

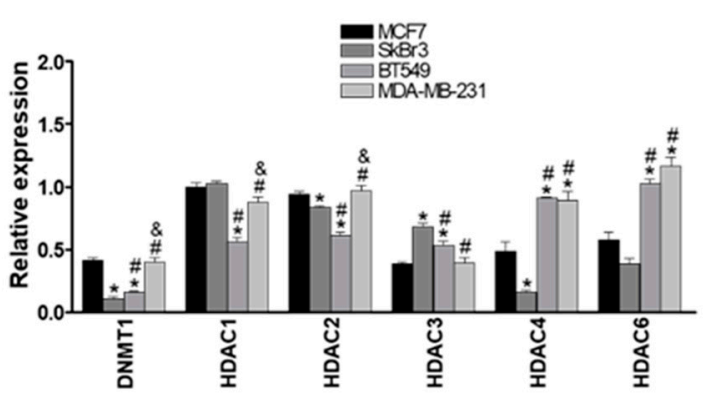

C

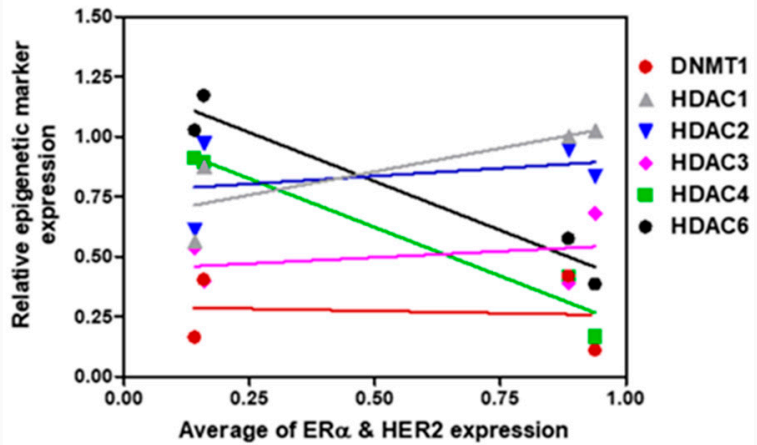

Figure 2. Differential expression of DNA methyltransferases (DNMT)1 and histone deacetylases (HDACs) in breast cancer cells. (A) Immunoblotting of DNMT1 and different HDACs in MCF7, SkBr3, BT-549 and MDA-MB-231. DNMT1 and HDAC1 were visualized on the same blot, HDAC2, HDAC6 and phospho- HDAC4,5 and 7 were visualized on another blot whereas HDAC 3 and 4 were visualized on a third blot (B) Quantification of band intensities of the indicated proteins. Each protein visualized on a blot was normalized to the corresponding $\beta$-actin as a loading control. (C) Correlations between the expression levels of ER $\alpha$ and HER2 and the expression levels of DNMT1, HDAC1, HDAC2, HDAC3, HDAC4 and HDAC6 in the indicated cell lines. Shown are the means \pm SEM of at least three independent experiments. ${ }^{*} p<0.05$ versus MCF7 cells, $\# p<0.05$ versus SkBr3 cells and \& $p<0.05$ versus BT-549 cells. Abbreviation: ns, not significant.

Table 2. Statistical parameters of correlation analysis between the expression levels of ER $\alpha$ and HER2 and the expression levels of epigenetic markers.

\begin{tabular}{lcc}
\hline & Correlation & \\
\hline Epigenetic Markers & r Values & $p$ Values \\
\hline DNMT1 & -0.1003 & $\mathrm{~ns}$ \\
HDAC1 & 0.8099 & $\mathrm{~ns}$ \\
HDAC2 & 0.3509 & $\mathrm{~ns}$ \\
HDAC3 & 0.3238 & $\mathrm{~ns}$ \\
HDAC4 & -0.9731 & 0.0269 \\
HDAC6 & -0.9711 & 0.0289
\end{tabular}

Indicated are the r values (Pearson's correlation coefficient) with the corresponding $p$ values.

These results reveal some differences in the expression of different epigenetic markers in the growth-promoting receptors positive cells with HDAC4 and HDAC6 being negative regulators of $\mathrm{ER} \alpha / \mathrm{HER} 2$ expression. 


\subsection{Effect of SAHA and/or 5-aza-dc on the Expression of Epigenetic Modulators}

Chromatin remodeling agents such as SAHA and 5-aza-dc can alter chromatin structure which may modify the expression status of many genes, leading to change in the response to cancer therapy. To address this issue, we investigated the effect of SAHA and 5-aza-dc on the expression levels of the epigenetic modifiers DNMT1 and HDACs. Firstly, the sensitivity of the four BC cell lines to SAHA (Supplementary Figure S2A) and 5-aza-dc (Supplementary Figure S2B) was measured by colony formation assay and the IC50 values were determined for each cell line (Supplementary Figure S2C). Results revealed that the growth-promoting receptor positive cell lines (MCF7 and SkBr3) were about 3-fold more sensitive to SAHA treatment than the TNBC cell lines, whereas the sensitivity to 5-aza-dc was independent on the expression level of these receptors (Supplementary Figure S2B).

Next, the effect of SAHA and/or 5-aza-dc on the expression levels of DNMT1 and different HDACs was measured by western blot after treating the cells with the respective IC50 concentrations (Figure 3A-D). We found that the expression of DNMT1 was significantly reduced upon treatment with SAHA in MCF7, SkBr3 and MDA-MB-231 cells (Figure 3A,B,D). Notably, SAHA treatment resulted in an unexpected increase in DNMT1 expression in BT549 cells (Figure 3C). 5-aza-dc treatment decreased the expression of DNMT1 in MCF7, BT-549, and MDA-MB-231 (Figure 3A,C,D) but not in SkBr3 cells (Figure 3B). Strikingly, combined SAHA and 5-aza-dc treatment decreased more efficiently the expression of DNMT1 in all four cell lines including BT549 cells, which showed an increase in the expression of DNMT1 upon treatment with SAHA (Figure 3C). On the other hand, the effect of the aforementioned drugs either individually or combined showed a differential effect on the expression profile of HDACs and their phosphorylation in the four cell lines. In MCF7 cells, a reduction in HDAC1 expression was reported upon treatment with SAHA and 5-aza-dc either combined or individually. On the other hand, a reduction in HDAC 2 expression was observed in MDA-MB-231 cells after SAHA and combined treatments (Figure 3A,D). Moreover, the expression of HDAC3 was down-regulated by SAHA, 5 -aza-dc and their combination in BT549 cells but only by 5-aza-dc in MDA-MB-231 cells. HDAC4 expression was significantly reduced after 5-aza-dc treatment in MCF7 and BT-549 cells (Figure 3A,C). Noteworthy, HDAC4 and HDAC6 were down-regulated upon combined 5-aza-dc and SAHA treatment more profoundly in TNBC cell lines. In addition, the phosphorylation levels of HDACs 4, 5, and 7 were reduced in all cell lines upon treatment with either SAHA alone or combined with 5-aza-dc. Together, these data reveal that the indicated epigenetic modifiers can generally alter the expression of DNMT1 and/or HDACs, which may result in modulating the chromatin structure and subsequently change gene expression.

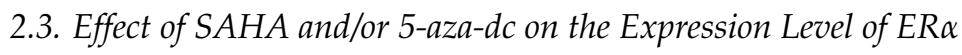

We next sought to investigate whether modifying the epigenome might increase the expression of $E R \alpha$. Thus, we examined the effect of SAHA and 5-aza-dc on the expression of ER $\alpha$ using western blot. Generally, our results revealed that treatment of the four cell lines with SAHA, 5-aza-dc or their combination showed different effects on the expression level of ER $\alpha$ (Figure 4; Supplementary Figure S3). An increase in ER $\alpha$ expression was shown upon SAHA treatment in BT-549 and MDA-MB-231 cells compared to MCF7 and SkBr3 cells (Figure 4A-D). 5-aza-dc treatment, on the other hand, enhanced the level of ER $\alpha$ in SkBr3, BT-549 and MDA-MB-231 and to lesser extent in MCF7 cells. Combined SAHA and 5-aza-dc treatment upregulated ER $\alpha$ expression in MCF7, SkBr3, and BT-549 cells (Figure 4A-C). Immunofluorescence analyses confirmed the upregulation of ER $\alpha$ by SAHA, 5-aza-dc and combined treatment in MCF7 and BT-549 cells (Figure 4E,F). Of note, the ER $\alpha$ expression was observed in the nucleus and cytoplasm compartments in both cell lines. SAHA resulted in a concentration-dependent increase in the level of ER $\alpha$ only in BT-549 cells (Figure 4G). On the other hand, 5-aza-dc upregulated the expression of ER $\alpha$ in both SkBr3 and MDA-MB-231 cells independent of drug concentration (Supplementary Figure S3B; Figure 4H). In contrast, this increase in the expression of ER $\alpha$ was not observed in MCF7 cells upon treatment with SAHA or 5-aza-dc (Figure 4A; Supplementary Figure S3A). These results were indeed further recapitulated using immunofluorescence staining (Supplementary 
Figure S3C,D). Collectively, these findings suggest that the expression of ER $\alpha$ can be modulated by SAHA or/and 5-aza-dc especially in TNBC cells.
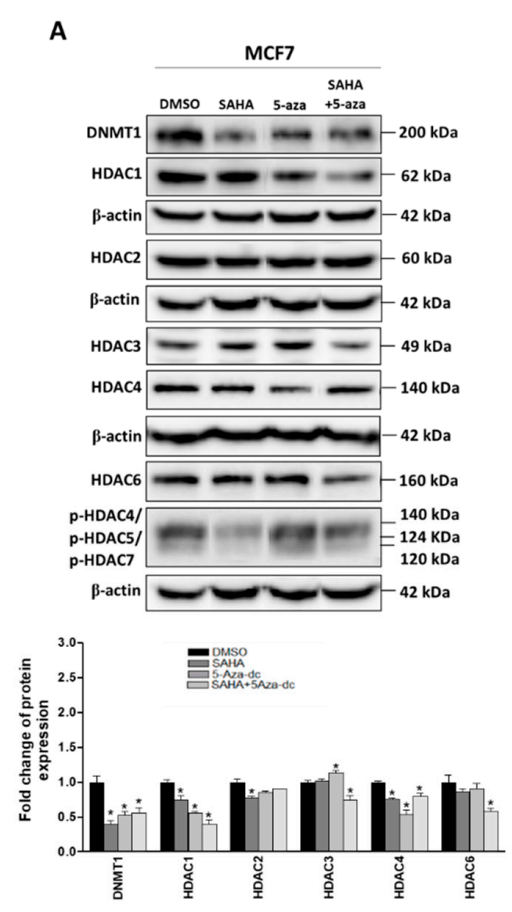

C
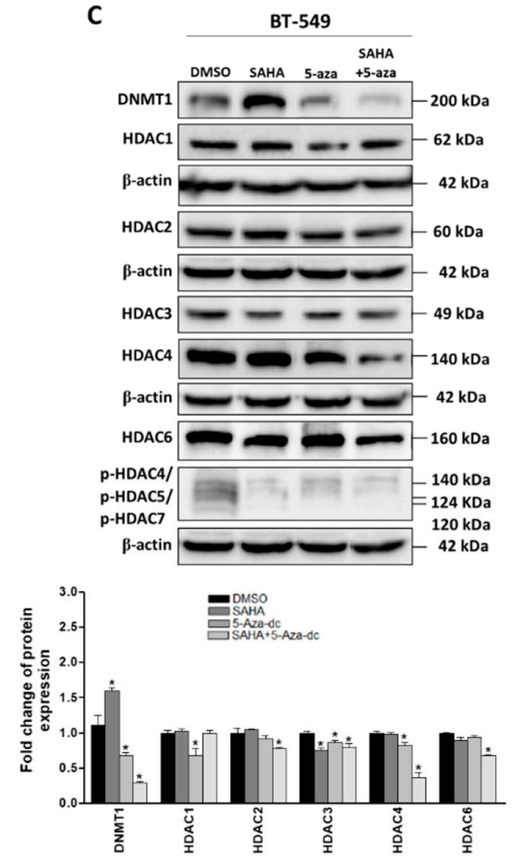
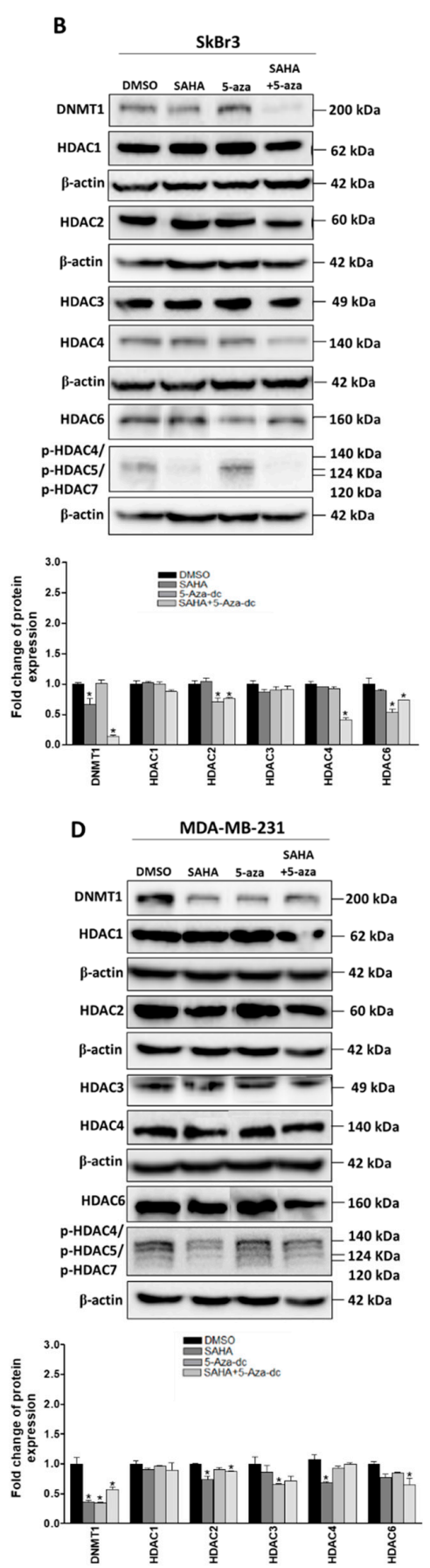

Figure 3. Effect of suberoylanilide hydroxamic acid (SAHA) and 5-aza-dc on the expression of epigenetic markers in breast cancer cells. Analysis of DNMT1, HDAC1, 2, 3, 4, 6, and p-HDAC 4/5/7 proteins upon treatment with IC50 concentrations of SAHA for $72 \mathrm{~h}$ or/and 5-aza-dc for $96 \mathrm{~h}$ in (A) MCF7, (B) SkBr3, (C) BT-549, and (D) MDA-MB-231. DNMT1 and HDAC1 were visualized on the same blot, HDAC2, HDAC6 and phospho- HDAC4,5 and 7 were visualized on another blot whereas HDAC 3 and 4 were visualized on a third blot. Bar graphs showing the relative fold change of DNMT1 and HDACs after normalization to $\beta$-actin expression and DMSO treatment. The level of each protein was normalized to the corresponding $\beta$-actin from the same blot. Shown are the means \pm SEM of at least three independent experiments. ${ }^{*} p<0.05$ versus DMSO group. 
A

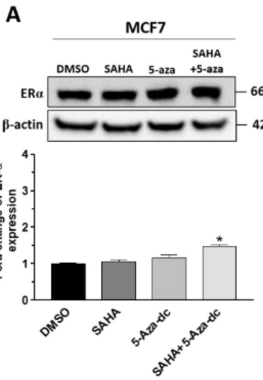

B SkBr3

C

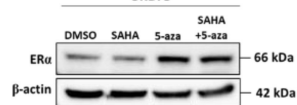

C $\quad$ BT-549

D MDA-MB-231

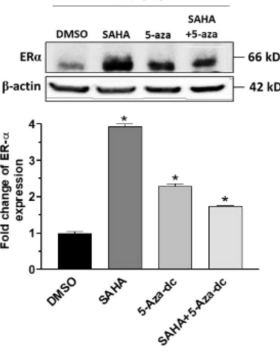

BRactin
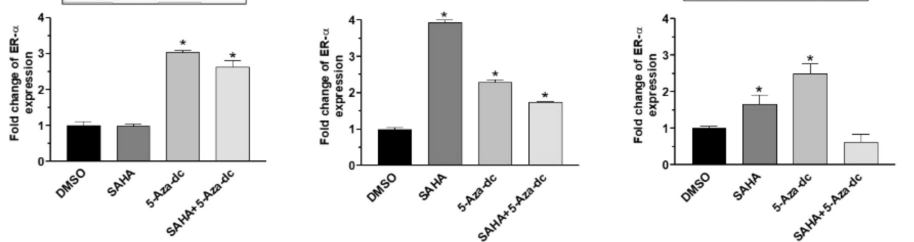

MCF7

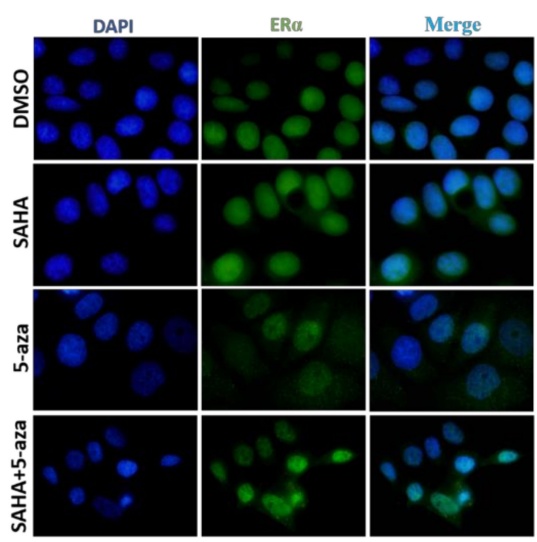

F
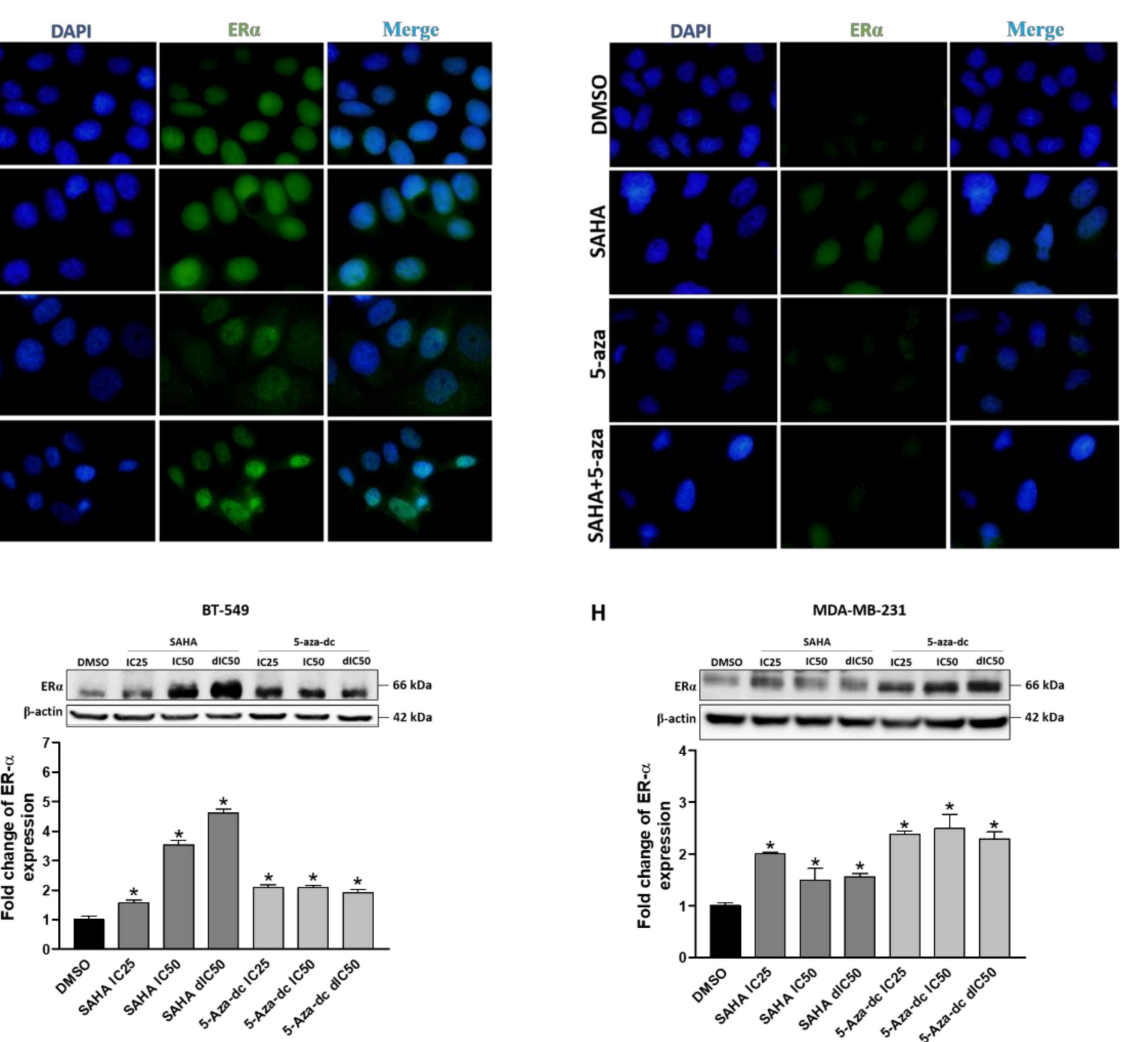

H

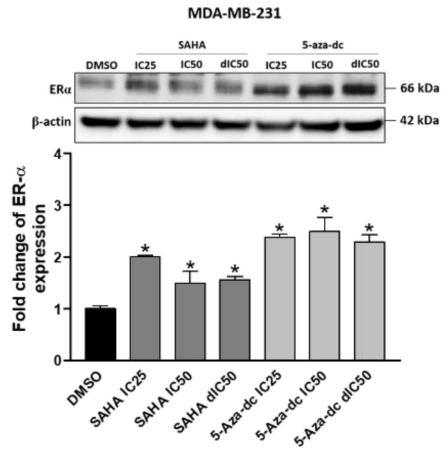

Figure 4. Effect of SAHA, 5-aza-dc and their combination on the expression of ER $\alpha$ in breast cancer cells. (A-D) Upper panels: Western blot analysis of ER $\alpha$ expression in (A) MCF7, (B) SkBr3, (C) BT549 and (D) MDA-MB-231 cells treated with the IC50 concentrations of SAHA and/or 5-aza-dc. Lower panel: Bar graphs showing relative fold changes of $E R \alpha$ bands after quantification and normalization to $\beta$-actin expression and DMSO treatment. (E,F) Representative micrographs (at 100 $\times$ magnification) of immunofluorescence staining of $\mathrm{ER} \alpha$ (green) and $4^{\prime}$,6-diamidino-2-phenylindole (DAPI)(blue) in (E) MCF7 and (F) BT-549 cells treated with SAHA and/or 5-aza-dc. (G,F) Western blots of ER $\alpha$ expression in (G) BT-549 and (H) MDA-MB-231 cells treated with IC25, IC50, and double IC50 (dIC50) concentrations of SAHA or 5-aza-dc. Shown are the means \pm SEM of at least three independent experiments. ${ }^{*} p<0.05$ versus DMSO group.

\subsection{Effect of SAHA and/or 5-aza-dc on the Expression Level of HER2/ERBB2}

HER2/ERBB2 expression was previously reported to affect the response to TAM [22]. Therefore, the effect of SAHA and/or 5-aza-dc treatment on the expression of HER2/ERBB2 was investigated by western blot and immunofluorescence. The two epigenetic modifying agents have differentially modulated the expression of HER2/ERBB2 in the four cell lines (Figure 5; Supplementary Figure S4). IC50 concentrations of SAHA enhanced the expression of HER2/ERBB2 in MCF7 and BT549 cells (Figure 5A-D). 5-aza alone or in combination with SAHA significantly increased the expression of HER2/ERBB2 in MCF7 cells with minor or even no effect on the other three cell lines. In addition, 
the IC25 and double IC50 concentrations of SAHA or 5-aza-dc more prominently upregulated the expression of HER2/ERBB2 in all cells (Figure 5G-J). HER2/ERBB2 upregulation was further confirmed in SkBr3 and BT-549 cells using immunofluorescence analysis (Figure 5E,F; Supplementary Figure $\mathrm{S} 4 \mathrm{~A}, \mathrm{~B})$. Of note, HER2/ERBB2 was detected at the membrane in SkBr3 cells whereas, it was found both in cytoplasm and nucleus in BT-549 cells. These data demonstrate that SAHA and/or 5-aza treatment alters the expression of HER2/ERBB2 in BC cells.
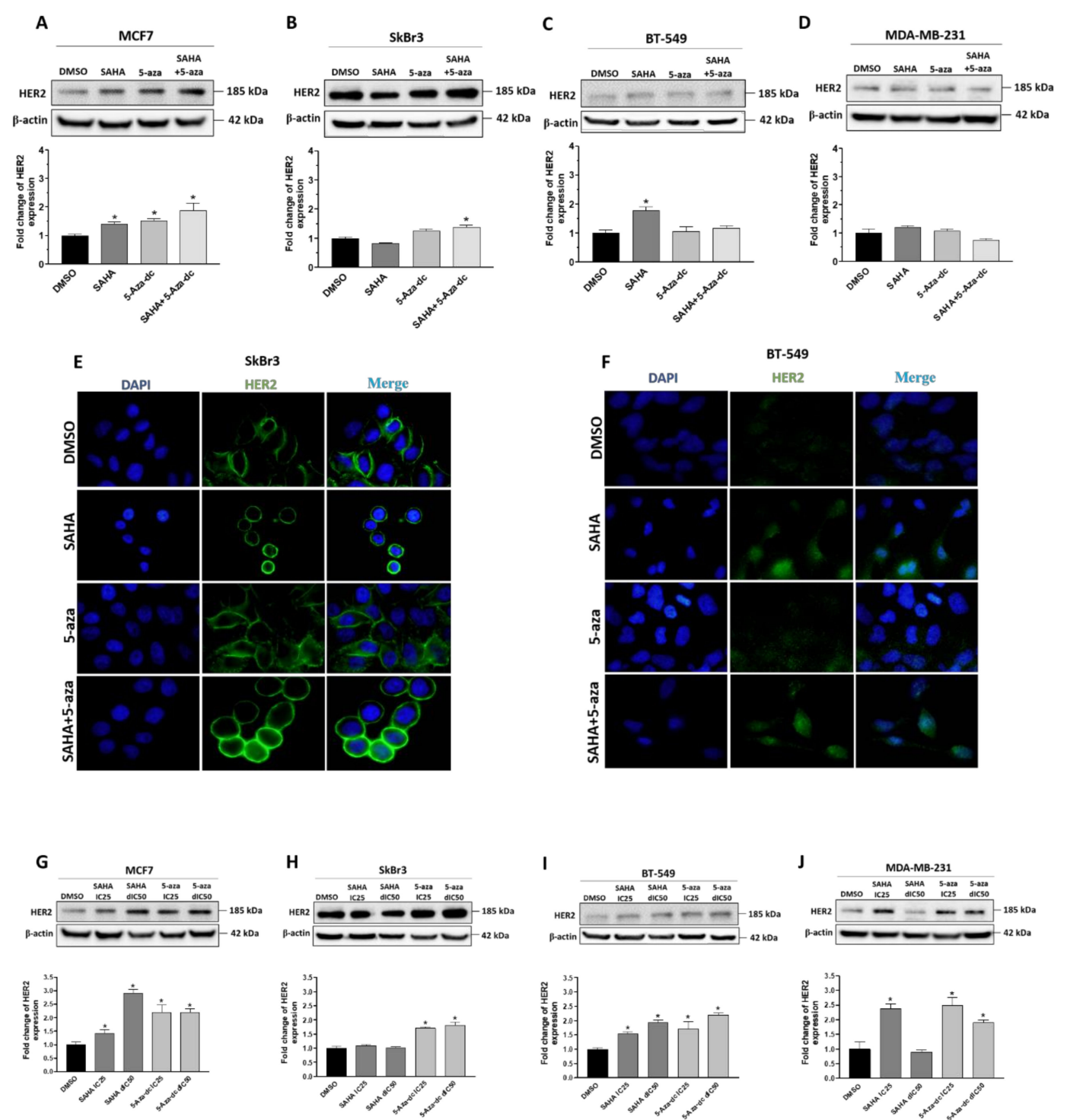

H

I

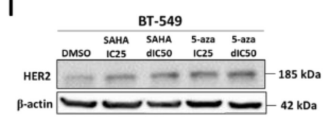

J MDA-MB-231

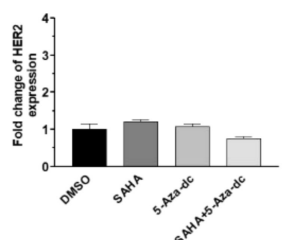

$-549$

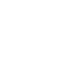

\author{
(n)
}




\subsection{Effect of SAHA and/or 5-aza-dc on the Response of Breast Cancer Cells to Hormonal Therapy}

Next, we sought to monitor the effect of ER $\alpha /$ HER2 upregulation-mediated by epigenetic modifiers - on the response of BC cells to hormonal therapy i.e., TAM. Therefore, colony formation assay was used to measure the sensitivity of the four $\mathrm{BC}$ cell lines to different concentrations $(0.01-10 \mu \mathrm{M})$ of TAM in combination with respective IC25 and IC50 concentrations of SAHA and/or 5-aza-dc (Table 3 and Supplementary Figure S5). MCF7 cells were found to be the most sensitive ( 2-fold) to TAM with an IC50 of $6.67 \pm 0.23 \mu \mathrm{M}$, while the other cell lines showed IC50 more than $10 \mu \mathrm{M}$. Importantly, the addition of IC25 concentrations of SAHA significantly increased the sensitivity of MDA-MB-231 ( 800 fold) but showed no effect on MCF7, BT549 and SkBr3 cells. Addition of IC50 concentrations of SAHA increased the response of MCF7 and both TNBC cells to TAM compared to $\mathrm{SkBr} 3$ cells. Similarly, the addition of IC50 or even the IC25 concentrations of 5-aza-dc increased the sensitivity of TAM in all cell lines. A similar increase in TAM sensitivity was reported in all cell lines upon combining with both SAHA and 5-aza-dc using IC25 or IC50 concentrations. Altogether, these results demonstrate that manipulating the epigenome could be an efficient strategy to enhance the response of TAM-resistant cells.

Table 3. IC50 values of SAHA and/or 5-aza-dc and their combination with TAM against four breast cancer cell lines.

\begin{tabular}{ccccc}
\hline & \multicolumn{4}{c}{ IC50 $(\mu \mathbf{M}) \pm$ SEM } \\
\hline Cell Line & MCF7 & SkBr3 & BT-549 & MDA-MB-231 \\
\hline SAHA & $0.600 \pm 0.034$ & $0.570 \pm 0.042$ & $1.500 \pm 0.089$ & $1.580 \pm 0.12$ \\
5-aza-dc & $0.040 \pm 0.0028$ & $0.080 \pm 0.0062$ & $1.040 \pm 0.074$ & $0.026 \pm 0.0011$ \\
SAHA + 5-aza-dc & $0.107 \pm 0.0312$ & $0.0284 \pm 0.0056$ & $0.0097 \pm 0.0021$ & $0.0082 \pm 0.0024$ \\
Tamoxifen & $6.4481 \pm 0.23$ & $>10$ & $>10$ & $>10$ \\
Tam + IC25 SAHA & $6.3241 \pm 0.31$ & $>10$ & $>10$ & $0.0126 \pm 0.00078$ \\
Tam + IC50 SAHA & $0.5420 \pm 0.014$ & $>10$ & $0.0022 \pm 0.0001$ & $0.0025 \pm 0.0001$ \\
Tam + IC25 5-aza-dc & $0.0117 \pm 0.0009$ & $0.0059 \pm 0.00024$ & $0.0022 \pm 0.0001$ & $0.0030 \pm 0.0002$ \\
Tam + IC50 5-aza-dc & $0.0031 \pm 0.00013$ & $0.0027 \pm 0.00008$ & $0.0021 \pm 0.00023$ & $0.0025 \pm 0.0001$ \\
Tam + IC25 SAHA + IC25 5-aza-dc & $0.0087 \pm 0.00035$ & $0.0022 \pm 0.0001$ & $0.0020 \pm 0.00008$ & $0.0021 \pm 0.00009$ \\
Tam + IC50 SAHA + IC50 5-aza-dc & $0.0024 \pm 0.00011$ & $0.0022 \pm 0.00009$ & $0.0020 \pm 0.00015$ & $0.0021 \pm 0.00007$ \\
\hline
\end{tabular}

Shown are the means \pm SEM of at least three independent experiments.

\subsection{Effect of SAHA and/or 5-aza-dc on Cell Cycle Distribution and Apoptosis in Breast Cancer Cells}

Having established the profound effect of both SAHA and/or 5-aza-dc as sensitizing agents to TAM, we therefore investigated whether these epigenetic modifiers may have cellular effects other than regulation of ER $\alpha$ expression. Thus, the effect of SAHA or/and 5-aza-dc on cell cycle progression as well as apoptosis was analyzed in the four cell lines using flow cytometry (Figure 6 and Supplementary Figure S6). Propidium iodide (PI) staining of the four cell lines treated with the respective IC50 concentrations of SAHA showed (i) a significantly increased accumulation of TNBC cells at G2 phase (BT-549: 1.7-fold, $p<0.0001$; MDA-MB-231: 1.2-fold, $p=0.0049$ ) and (ii) an increase in G1 phase fraction in MCF7 and BT549 cells. On the other hand, 5-aza-dc induced a G1-arrest exclusively in BT-549 cells (1.1-fold). The effect of combined treatment of TAM with SAHA or 5-aza-dc resulted in a G1 arrest in both MCF7 and BT-549 cells.

Apoptosis-indicated by the percentage of sub-G1 cells-was induced significantly in the four cell lines after treatment with SAHA, 5-aza and their combination (Figure 6B). Importantly, the combination of these epigenetic modifiers with TAM further increased apoptosis more apparently in TNBC cells (Figure 6B). The expression of different apoptotic markers after treatment with SAHA and/or 5-aza-dc was examined in the four cell lines using western blot (Supplementary Figure S7). On the one hand, IC50 concentrations of SAHA reduced the expression of the apoptotic agonist BID in MCF7, SkBr3 and MDA-MB-231 and enhanced caspase 3 cleavage in BT-549 cells (Supplementary Figure $\mathrm{S7C}$ ). On the other hand, 5-aza-dc treatment increased (i) the expression of p53 in all cell lines (ii) 
caspase 9 cleavage in MCF7 cells and (iii) caspase 3 cleavage in the other three cell lines. Noteworthy, SAHA or 5-aza-dc treatment changed the expression level of caspase 3, 8 and 9 in MDA-MB-231 cells more than the other cell lines (Supplementary Figure S7D). The combination of SAHA and 5-aza-dc reduced (i) the expression of bcl-xl in MCF7 cells and (ii) the expression of BID in MCF7 and TNBC cells. These data indicate that both SAHA and 5-aza-dc exert their effect additional through apoptosis induction, however through different mechanisms. While, SAHA induces apoptosis probably through downregulating the anti-apoptotic factors bcl-xl and BID, 5-aza-dc does this through stimulating the expression of p53 and increasing the processing of caspases 3 and 9.
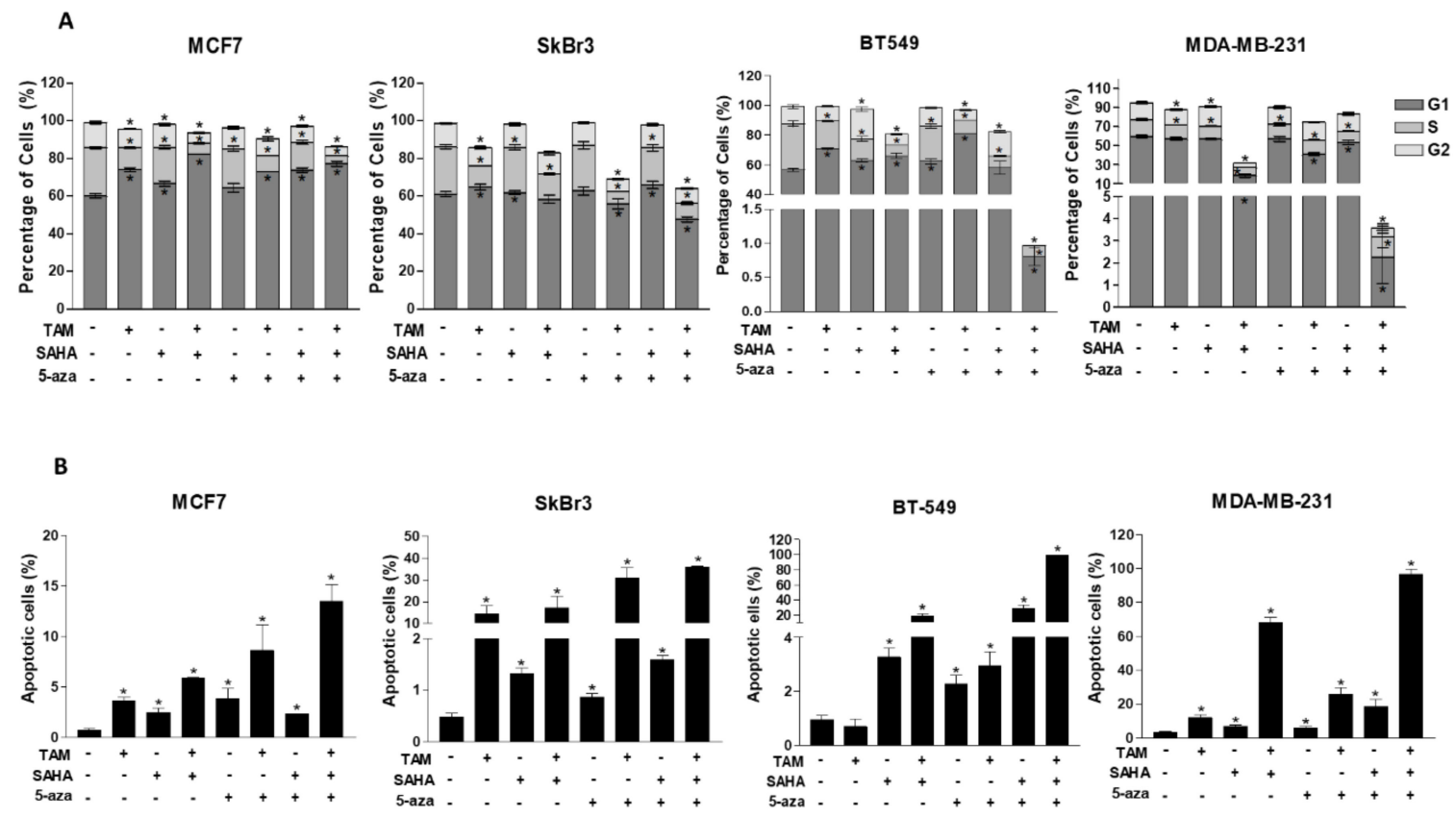

Figure 6. Effect of TAM, SAHA, 5-aza-dc and their combination on cell cycle distribution. (A) Bar graphs showing the percentage of cells in each cell cycle phase after treatment of MCF7, SkBr3, BT-549 and MDA-MB-231 cells with IC50 concentrations of SAHA and/or 5-aza-dc and their combination with the IC50 concentration of TAM. (B) Percentage of sub-G1 cells (apoptotic cells) for each cell line is indicated. Shown are the means \pm SEM of at least three independent experiments. * $p<0.05$ versus DMSO group.

\section{Discussion}

Aberrant epigenetic modifications have been shown to play an important role in BC tumorigenesis, progression, and treatment response, through impacting DNA repair, cell cycle, apoptosis and hormonal regulation [23,24]. Accordingly, modulating DNA methylation and histone acetylation might be a promising therapeutic strategy in breast cancer. In the current study, we report different expression patterns of epigenetic markers such as DNMT1 and different HDACs in four BC cell lines that differ basically in the expression of ER $\alpha$ and HER2/ERBB2 ([25] and results reported herein). This is consistent with the clinical studies that showed differential expression of HDACs 1,2, and 3 in BC patients with different hormonal status [26]. DNMT1 was unexpectedly low in the TNBC cell line 'BT-549' compared to that in MCF7 and MDA-MB-231 cells, because DNA methylation is partly involved in ER $\alpha$ and HER2/ERBB2 gene silencing [27]. Indeed, several other methyltransferases such as DNMT3b were shown to be responsible for silencing ER $\alpha$ and HER2/ERBB2 genes [28]. Further, we report here that HDAC4 and 6 are stronger regulators of ER $\alpha$ and HER2/ERBB2 expression than other HDACs. HDAC4 / 6 were found to be highly expressed in BT549 and MDA-MB-231 cells, which have low levels of ER $\alpha$ and HER2/ERBB2. Vice versa, HDAC 4 and 6 expressions were low in MCF7 and SkBr3 cells that have high expression of ER $\alpha$ and overexpression of HER2/ERBB2, 
respectively. These results are consistent with a previous observation in ER $\alpha$-negative cells where HDAC 6 overexpression was described [29]. We report here that ER $\alpha$ but not HER2/ERBB2 expression level can predict TAM sensitivity in the four cell lines. Previously, HER2 overexpression was found to associate with TAM resistance in BC, properly through a crosstalk with ER $\alpha$ signaling pathway [22,30]. The discrepancy between these studies and ours could be attributed to other cytotoxic effects of TAM such as induction of apoptosis and cell cycle modifications which might overcome the estrogenic (anti-TAM) effects induced by HER2 expression.

An interplay between DNA methylation and histone deacetylation to modify the expression level of some genes has been previously reported by Jones et al., where HDAC was shown to be recruited at the promoter area of the target gene after attachment of 5-methylcytosine binding protein [31]. This crosstalk was the foundation to investigate the effect of combining 5-aza-dc and SAHA on the expression level of different genes in our panel of cell lines. In the present study, SAHA and 5-aza-dc showed differential effects on the expression of DNMT1 and HDACs. In consistent with previous reports [32], the expression of HDAC 1 or 2 was not modified in ER $\alpha$-negative cell lines upon treatment with SAHA. However, SAHA treatment decreases the expression of (i) HDAC1 in MCF7, (ii) HDAC2 in MDA-MB-231, and (iii) HDACs 3 in BT-549 cells. This is most likely due to modulation of the chromatin structure by SAHA that would affect the normal transcription level of some genes [33]. Interestingly, a reduction in the expression of HDACs 4 and 6 was detected upon treatment with 5-aza-dc and its combination with SAHA. This indeed supports the interplay between DNA methylation and histone acetylation in chromatin remodeling [34,35].

The reported modulation of ER $\alpha /$ HER2 expression by SAHA and/or 5-aza-dc, especially in TNBC cells, suggests that epigenetic modifications might have a role in regulating the expression of these receptors. Based on our findings, we hypothesize that (i) the decreased HDACs levels/activities mediated by SAHA stimulates $\mathrm{H} 3$ and/or $\mathrm{H} 4$ acetylation at ER $\alpha$ promoter and (ii) the decreased level/activity of DNMT by 5-aza-dc compromises the methylation at certain CpG sites within ER $\alpha$ promoter. These epigenetic modifications allow an open chromatin state at the promoter of the ER $\alpha /$ HER2 genes, thus enhancing the expression of both receptors. This indeed in line with previously published data showing that the HDAC inhibitor Trichostatin A and 5-aza-dc modulate chromatin structure at ER promoter in TNBC cells MDA-MB-231 through increasing H3 and H4 acetylation and partial demethylation of $\mathrm{CpG}$ islands respectively [36]. The concentration-dependent upregulation of ER $\alpha$ by SAHA in TNBC cells further supports this finding. However, the effect of combining SAHA and 5-aza-dc on ER $\alpha$ expression was found to be similar to the effect observed for single treatment. This can be explained by the existence of a ceiling effect for ER $\alpha$ expression that can be achieved by a single treatment and cannot be exceeded upon combined treatment. In line with this, Pryzbylkowski et al. demonstrated a reduction in ER $\alpha$ mRNA stability upon combination treatment with 5-aza-dc and Trichostatin-A through reducing cytoplasmic levels of the RNA-binding protein HuR that is responsible for ER $\alpha$ mRNA stabilization [37].

The upregulation of ER $\alpha$ expression observed after SAHA and/or 5-aza-dc tempted us to use these epigenetic modifiers to sensitize TNBC cells to hormonal therapy such as TAM. Strikingly, we report an enhanced response of BC cells to TAM upon combination with either of the aforementioned epigenetic modifier. This could be partly but not exclusively attributed to ER $\alpha$ upregulation by SAHA or/and 5-aza-dc. SAHA and/or 5-aza-dc increased the expression of ER $\alpha$ by 4-5 folds, yet they increased the sensitivity to TAM by several hundred times. Previously, several reports suggested that HDAC inhibitors (SAHA and Trichostatin-A) and demethylating agents (zebularine and 5-aza-dc) induce apoptosis in different cancer types including BC [38-41]. Consistently, we report that SAHA or/and 5-aza-dc and their combination with TAM enhanced apoptosis and arrested the cells in G1 or G2, importantly with greater impact on TNBC cells.

Collectively, we propose here a mechanistic model for targeting TNBC cells using epigenetic modifiers to enhance TAM sensitivity (Figure 7). SAHA and 5-aza-dc induce chromatin modifications mainly by changing the expression of DNMT1 and HDACs 4 and 6. Subsequently, these modifications 
upregulate the expression of ER $\alpha$ and HER2/ERBB2, as well as, induce cell cycle arrest and apoptosis. These cellular changes eventually enhance the response of TNBC cells to TAM.

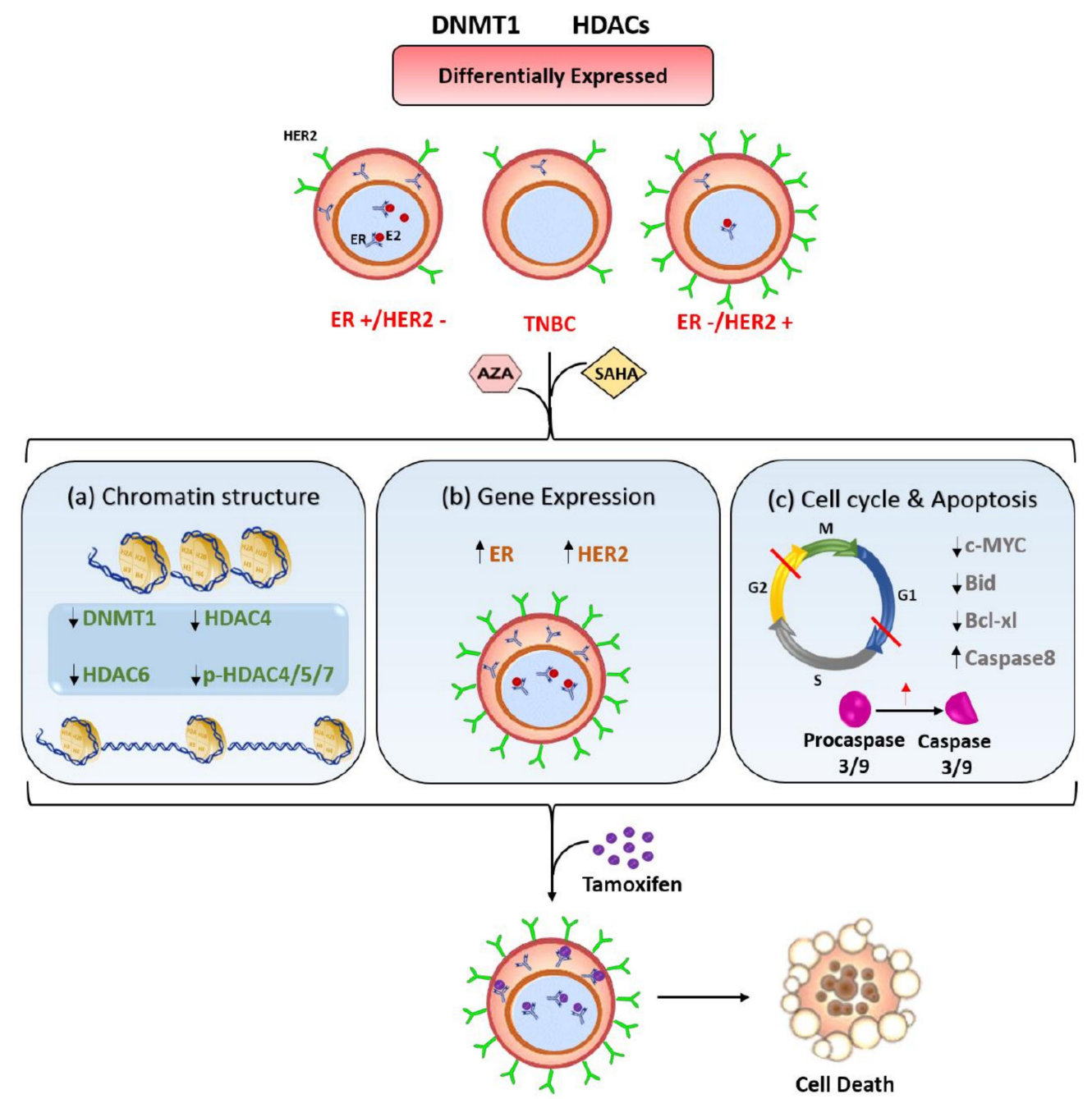

Figure 7. Model for the effect of SAHA and 5-aza-dc on the response of TNBC cells to TAM. BC cells with different hormonal status vary in the expression pattern of DNMT1 and different HDACs. Epigenetic modifiers such as SAHA and 5-aza-dc result in (a) modifying the chromatin structure by reducing DNMT1 expression and inhibiting the activity and phosphorylation of different HDACs, (b) upregulating the expression of ER $\alpha$ and HER2/ERBB2 and (c) arresting the cell cycle in G1 and G2 phases and inducing apoptosis. These changes consequently increase the response of TNBC cells to TAM.

\section{Materials and Methods}

\subsection{Cell Lines and Culture Conditions}

Four human BC cell lines (MCF-7, BT-549, SkBr3 and MDA-MB-231) were employed in the present study. All cell lines were maintained in RPMI or DMEM medium supplemented with $10 \%$ fetal bovine serum and 1\% penicillin/streptomycin (Sigma Aldrich, St. Louis, MO, USA) in a $37^{\circ} \mathrm{C}$ humidified incubator and an atmosphere of $5 \% \mathrm{CO}_{2}$. The expression status of the hormone receptors ER, PR and Her2/ErBB2 in these four cell lines are shown in Table 4. 
Table 4. Expression status of ER $\alpha$, PR, and HER2/ERBB2 in four breast cancer cell lines [25].

\begin{tabular}{cccc}
\hline Cell Line & $\begin{array}{c}\text { Estrogen Receptor } \boldsymbol{\alpha} \\
\text { (ER } \boldsymbol{\alpha})\end{array}$ & $\begin{array}{c}\text { Progesterone Receptor } \\
\text { (PR) }\end{array}$ & $\begin{array}{c}\text { HER2/ERBB2 } \\
\text { (Overexpression) }\end{array}$ \\
\hline MCF7 & Yes & Yes & No \\
SkBr3 & No & No & Yes \\
BT-549 & No & No & No \\
MDA-MB-231 & No & No & No \\
\hline
\end{tabular}

\subsection{Colony Formation Assay}

Sensitivity to tamoxifen, SAHA and 5-AZA was tested using colony formation assay as previously described [42]. Briefly, cells were cultured at different numbers (50-1200) in T25 $\mathrm{cm}^{2}$ culture flasks. After $24 \mathrm{~h}$, cells were treated with either $0.01-10 \mu \mathrm{M}$ of SAHA for $72 \mathrm{~h}$ or $0.01-10 \mu \mathrm{M}$ of 5-aza-dc (Sigma Aldrich) for $96 \mathrm{~h}$. In combination treatments, cells were treated with $0.01-10 \mu \mathrm{M}$ of tamoxifen (Sigma Aldrich) alone or in combination with IC25 or IC50 concentrations of SAHA. For combination with 5-aza-dc, the treatment started with 5 -aza-dc for $24 \mathrm{~h}$ followed by the addition of tamoxifen and/or SAHA. DMSO (Sigma-Aldrich) was used as a control. DMSO concentration was $<0.01 \%$ in all experiments. At the end of the treatment period, the drug-containing medium was replaced with drug-free medium and cells were further incubated. Colonies were then fixed with $70 \%$ of ethanol for $30 \mathrm{~min}$ and stained with $1 \%$ crystal violet (Sigma-Aldrich) for $5 \mathrm{~min}$ at room temperature. The number of colonies at each treatment was counted for the calculation of both platting efficiency and surviving fraction. The IC50 values were calculated by sigmoidal curve fitting models using Graph Pad Prism 3 software (GraphPad Software, San Diego, CA, USA).

\subsection{Sulforhodamine B (SRB) Assay}

Anti-proliferative effect of tamoxifen was investigated using sulforhodamine B assay (Sigma-Aldrich), according to manufacturer's protocol [43]. Briefly, cells were cultured at density of 7000 cells /well in a 96-well plate format. After $24 \mathrm{~h}$, cells were treated with 1-160 $\mu \mathrm{M}$ of tamoxifen for further $72 \mathrm{~h}$. Thereafter, cells were fixed with $50 \%$ trichloroacetic acid for $1 \mathrm{~h}$ at $4{ }^{\circ} \mathrm{C}$. Plates were washed 9 times with water and stained with $0.4 \%$ SRB for $30 \mathrm{~min}$ at room temperature. After washing with $1 \%$ acetic acid, the dye was solubilized in $200 \mu \mathrm{L}$ of $10 \mathrm{mM}$ Tris base for $10 \mathrm{~min}$. The optical density (OD) was measured at $492 \mathrm{~nm}$ in a microplate reader Varioskan ${ }^{\text {TM }}$ Flash (Thermo Fisher Scientific, Waltham, MA, USA)

\subsection{Western Blot}

Western blot was conducted as previously described [44]. Cells were washed with $1 \times$ phosphate buffered saline (PBS) (Sigma Aldrich) and harvested with lysis buffer containing 20\% SDS, glycerol, $1 \mathrm{M}$ Tris (pH 6.8) and protease inhibitor cocktail (Sigma-Aldrich). Equal amounts of total protein (30 $\mu \mathrm{g})$ were separated on $12 \%$ SDS polyacrylamide gel and transblotted onto polyvinylidene difluoride (PVDF) membrane (Biorad, Hercules, CA, USA). The membranes were blocked with $5 \%$ non-fat dried milk in 1X TBS-Tween 20 and then incubated with primary antibodies at a dilution of 1:1000. The following antibodies were used: ER $\alpha$ (D8H8) Rabbit mAb \#8644, HER2/ErbB2 Rabbit pAb \#2242, HDAC1 (10E2) Mouse mAb \#5356, HDAC2 (3F3) Mouse mAb \#5113, HDAC3 (7G6C5) Mouse mAb \#3949, HDAC4 (D15C3) Rabbit mAb \#7628, HDAC6 (D2E5) Rabbit mAb \#7558, Phospho-HDAC4 (Ser246)/HDAC5 (Ser259)/HDAC7 (Ser155) (D27B5) Rabbit mAb \#3443, DNMT1 (D63A6) XP ${ }^{\circledR}$ Rabbit mAb \#5032, BID Antibody (Human Specific) Rabbit pAb \#2002, Bcl-xL (54H6) Rabbit mAb \#2764, c-Myc (D84C12) Rabbit mAb \#5605, Caspase-3 (8G10) Rabbit mAb \#9665, Caspase-8 (1C12) Mouse mAb \#9746 and Caspase-9 (C9) Mouse mAb \#9508 (purchased from Cell Signaling Technology, Danvers, MA, USA), p53 (DO-1) Mouse mAb \#sc126 (Santa Cruz Biotechnology, Dallas, TX, USA) and Anti- $\beta$-Actin Clone AC-15 Mouse mAB \#A5441 (Sigma Aldrich) for overnight at $4{ }^{\circ} \mathrm{C}$. The secondary antibodies Anti-rabbit IgG, HRP-linked Antibody \#7074 and Anti-mouse IgG, HRP-linked Antibody \#7076 (Cell Signaling 
Technology) were prepared at dilution of 1:2000 and incubated with membrane at room temperature for $1 \mathrm{~h}$. The membranes were then washed 3 times with $1 \times$ TBS-T. Chemiluminescence was detected by ECL method (Thermo Fisher Scientific) and developed by ChemiDoc ${ }^{\mathrm{TM}}$ imaging system (Biorad). Quantification of bands was analyzed by Image $\mathrm{Lab}^{\mathrm{TM}}$ software (Biorad).

\subsection{Immunofluorescence}

Immunofluorescence detection of ER $\alpha$ and HER2/ERBB2 was performed as previously described [45]. Cells were cultured on coverslips and at the end of the treatment period, cells were fixed with $4 \%$ formaldehyde, permeabilized with $0.5 \%$ Triton-X (Sigma-Aldrich) and blocked with $4 \%$ BSA in humidifying chamber for $20 \mathrm{~min}$. Coverslips were then incubated with ER $\alpha$ (D8H8) Rabbit mAb \#8644 or HER2/ErbB2 (29D8) Rabbit mAb \#2165 (Cell Signaling Technology) at a dilution of 1:250 for $1 \mathrm{~h}$ at room temperature, followed by an addition of fluorescine iso-thiocyanate (FITC)-conjugated secondary antibody \#4412 (Cell Signaling Technology) at a 1:500 dilution for $45 \mathrm{~min}$ at room temperature. After washing, cells were mounted on glass slides with prolong antifade reagent with DAPI (Cell Signaling Technology). Cells were then visualized by BX51P fluorescence microscope (Olympus, Tokyo, Japan) at $100 \times$ magnification.

\subsection{Cell Cycle Analysis}

Effects on cell cycle were analyzed using flow cytometry as previously described [46]. At the end of treatment period, cells were harvested, washed with $1 \times$ PBS and then fixed in 70\% ethanol for $24 \mathrm{~h}$ at $4{ }^{\circ} \mathrm{C}$. The fixed cells were washed 2 times with $1 \times$ PBS and incubated in $1 \times$ PBS containing RNAase $(100 \mu \mathrm{g} / \mathrm{mL})$ for $30 \mathrm{~min}$ at $37^{\circ} \mathrm{C}$. Fixed cells were subsequently stained with propidium iodide $(50 \mu \mathrm{g} / \mathrm{mL})$ and analyzed using FACScan flow cytometry (Becton Dickenson, San Jose, CA, USA). DNA histograms and data analysis, including the calculation of sub-G1 population were performed with FlowJo V.10 software (Tree Star, Inc, Ashland, OR, USA) as previously described [47].

\subsection{Statistical Analysis}

All experiments were carried out in triplicate and repeated at least 3 times. Data are expressed as means \pm SEM. Statistical analysis was performed by unpaired student's $t$-test using Graph Pad Prism software (GraphPad Software). $p<0.05$ was considered statistically significant. The linear regression and Pearson's correlation coefficient (r) was calculated using Graph Pad Prism software (GraphPad Software)

\section{Conclusions}

Collectively, we report that SAHA and 5-aza-dc either individually or in combination (i) modulate the expression of some epigenetic regulators i.e., DNMT1 and HDACs, (ii) increase the expression of ER $\alpha$ especially in ER-negative cells, and eventually (iii) sensitize breast cancer cells to TAM treatment. These findings need to be confirmed using animal models and subsequent clinical trials. Clinically, our data provides the proof-of-concept of using epigenetic modifiers to sensitize TNBC cells to hormonal therapy.

Supplementary Materials: The following are available online at http:/ /www.mdpi.com/2072-6694/11/1/13/s1, Figure S1: The response of breast cancer cells to TAM and the correlation analysis with ER $\alpha$ and HER2/ERBB2 expression, Figure S2: Effect of SAHA and 5-aza-dc on survival of breast cancer cells, Figure S3: Effect of SAHA and 5-aza-dc on the expression of ER $\alpha$ in breast cancer cells, Figure S4: Effect of SAHA and 5-aza-dc on the expression of HER2/ERBB2 in breast cancer cells, Figure S5: Effect of SAHA and/or 5-aza-dc on the sensitivity of breast cancer cells to TAM, Figure S6: Effect of TAM, SAHA, 5-aza-dc and their combination on cell cycle distribution, Figure S7: Effect of SAHA, 5-aza-dc and their combination on apoptosis in breast cancer cells.

Author Contributions: Conceptualization, R.E.-A. and W.S.R.; Methodology, W.S.R., E.M.S., C.G.V., A.M.A. and V.M.; Formal analysis, A.T.E.-S.; Data curation, R.E.-A., W.M. and W.S.R.; Writing-original draft preparation, R.E.-A. and W.S.R; Writing-review and editing, W.M.; Supervision, R.E.-A. and A.T.E.S.; Project administration, R.E.-A.; Funding acquisition, R.E.-A. 
Funding: This research was funded by University of Sharjah, grant number 16011103017-p.

Conflicts of Interest: The authors declare no conflict of interest. The funder had no role in the design of the study; in the collection, analyses, or interpretation of data; in the writing of the manuscript, or in the decision to publish the results.

\section{References}

1. Russnes, H.G.; Lingjaerde, O.C.; Borresen-Dale, A.L.; Caldas, C. Breast Cancer Molecular Stratification: From Intrinsic Subtypes to Integrative Clusters. Am. J. Pathol. 2017, 187, 2152-2162. [CrossRef] [PubMed]

2. Bianchini, G.; Balko, J.M.; Mayer, I.A.; Sanders, M.E.; Gianni, L. Triple-negative breast cancer: Challenges and opportunities of a heterogeneous disease. Nat. Rev. Clin. Oncol. 2016, 13, 674-690. [CrossRef] [PubMed]

3. Podo, F.; Buydens, L.M.; Degani, H.; Hilhorst, R.; Klipp, E.; Gribbestad, I.S.; Van Huffel, S.; van Laarhoven, H.W.; Luts, J.; Monleon, D.; et al. Triple-negative breast cancer: Present challenges and new perspectives. Mol. Oncol. 2010, 4, 209-229. [CrossRef] [PubMed]

4. Peddi, P.F.; Ellis, M.J.; Ma, C. Molecular basis of triple negative breast cancer and implications for therapy. Int. J. Breast Cancer 2012, 2012, 217185. [CrossRef] [PubMed]

5. Diana, A.; Franzese, E.; Centonze, S.; Carlino, F.; Della Corte, C.M.; Ventriglia, J.; Petrillo, A.; De Vita, F.; Alfano, R.; Ciardiello, F.; et al. Triple-Negative Breast Cancers: Systematic Review of the Literature on Molecular and Clinical Features with a Focus on Treatment with Innovative Drugs. Curr. Oncol. Rep. 2018, 20, 76. [CrossRef] [PubMed]

6. Shi, Y.; Jin, J.; Ji, W.; Guan, X. Therapeutic landscape in mutational triple negative breast cancer. Mol. Cancer 2018, 17, 99. [CrossRef] [PubMed]

7. Al-Mahmood, S.; Sapiezynski, J.; Garbuzenko, O.B.; Minko, T. Metastatic and triple-negative breast cancer: Challenges and treatment options. Drug Deliv. Transl. Res. 2018, 8, 1483-1507. [CrossRef] [PubMed]

8. Lebert, J.M.; Lester, R.; Powell, E.; Seal, M.; McCarthy, J. Advances in the systemic treatment of triple-negative breast cancer. Curr. Oncol. 2018, 25, S142-S150. [CrossRef]

9. Yao, H.; He, G.; Yan, S.; Chen, C.; Song, L.; Rosol, T.J.; Deng, X. Triple-negative breast cancer: Is there a treatment on the horizon? Oncotarget 2017, 8, 1913-1924. [CrossRef]

10. Sharma, S.; Kelly, T.K.; Jones, P.A. Epigenetics in cancer. Carcinogenesis 2010, 31, 27-36. [CrossRef]

11. Strauss, J.; Figg, W.D. Using Epigenetic Therapy to Overcome Chemotherapy Resistance. Anticancer Res. 2016, 36, 1-4. [PubMed]

12. Connolly, R.; Stearns, V. Epigenetics as a therapeutic target in breast cancer. J. Mammary Gland Biol. Neoplasia 2012, 17, 191-204. [CrossRef] [PubMed]

13. Chen, E.S. Targeting epigenetics using synthetic lethality in precision medicine. Cell. Mol. Life Sci. 2018, 75, 3381-3392. [CrossRef] [PubMed]

14. Howell, P.M.; Liu, Z.; Khong, H.T. Demethylating Agents in the Treatment of Cancer. Pharmaceuticals 2010, 3, 2022-2044. [CrossRef] [PubMed]

15. Platzbecker, U.; Middeke, J.M.; Sockel, K.; Herbst, R.; Wolf, D.; Baldus, C.D.; Oelschlagel, U.; Mutherig, A.; Fransecky, L.; Noppeney, R.; et al. Measurable residual disease-guided treatment with azacitidine to prevent haematological relapse in patients with myelodysplastic syndrome and acute myeloid leukaemia (RELAZA2): An open-label, multicentre, phase 2 trial. Lancet Oncol. 2018, 19, 1668-1679. [CrossRef]

16. Schnekenburger, M.; Grandjenette, C.; Ghelfi, J.; Karius, T.; Foliguet, B.; Dicato, M.; Diederich, M. Sustained exposure to the DNA demethylating agent, 2'-deoxy-5-azacytidine, leads to apoptotic cell death in chronic myeloid leukemia by promoting differentiation, senescence, and autophagy. Biochem. Pharmacol. 2011, 81, 364-378. [CrossRef] [PubMed]

17. De Souza, C.; Chatterji, B.P. HDAC Inhibitors as Novel Anti-Cancer Therapeutics. Recent Pat. Anticancer Drug Discov. 2015, 10, 145-162. [CrossRef]

18. Ghayad, S.E.; Rammal, G.; Sarkis, O.; Basma, H.; Ghamloush, F.; Fahs, A.; Karam, M.; Harajli, M.; Rabeh, W.; Mouawad, J.E.; et al. The histone deacetylase inhibitor Suberoylanilide Hydroxamic Acid (SAHA) as a therapeutic agent in rhabdomyosarcoma. Cancer Biol. Ther. 2018, 1-12. [CrossRef]

19. Min, A.; Im, S.A.; Kim, D.K.; Song, S.H.; Kim, H.J.; Lee, K.H.; Kim, T.Y.; Han, S.W.; Oh, D.Y.; Kim, T.Y.; et al. Histone deacetylase inhibitor, suberoylanilide hydroxamic acid (SAHA), enhances anti-tumor effects 
of the poly (ADP-ribose) polymerase (PARP) inhibitor olaparib in triple-negative breast cancer cells. Breast Cancer Res. 2015, 17, 33. [CrossRef]

20. Tang, Y.; Wang, Y.; Kiani, M.F.; Wang, B. Classification, Treatment Strategy, and Associated Drug Resistance in Breast Cancer. Clin. Breast Cancer 2016, 16, 335-343. [CrossRef]

21. Ciocca, D.R.; Elledge, R. Molecular markers for predicting response to tamoxifen in breast cancer patients. Endocrine 2000, 13, 1-10. [CrossRef]

22. Arpino, G.; Wiechmann, L.; Osborne, C.K.; Schiff, R. Crosstalk between the estrogen receptor and the HER tyrosine kinase receptor family: Molecular mechanism and clinical implications for endocrine therapy resistance. Endocr. Rev. 2008, 29, 217-233. [CrossRef] [PubMed]

23. Stefansson, O.A.; Esteller, M. Epigenetic modifications in breast cancer and their role in personalized medicine. Am. J. Pathol. 2013, 183, 1052-1063. [CrossRef]

24. Wu, Y.; Sarkissyan, M.; Vadgama, J.V. Epigenetics in breast and prostate cancer. Methods Mol. Biol. 2015, 1238, 425-466. [CrossRef] [PubMed]

25. Holliday, D.L.; Speirs, V. Choosing the right cell line for breast cancer research. Breast Cancer Res. 2011, 13, 215. [CrossRef] [PubMed]

26. Muller, B.M.; Jana, L.; Kasajima, A.; Lehmann, A.; Prinzler, J.; Budczies, J.; Winzer, K.J.; Dietel, M.; Weichert, W.; Denkert, C. Differential expression of histone deacetylases HDAC1, 2 and 3 in human breast cancer-Overexpression of HDAC2 and HDAC3 is associated with clinicopathological indicators of disease progression. BMC Cancer 2013, 13, 215. [CrossRef] [PubMed]

27. Sunami, E.; Shinozaki, M.; Sim, M.S.; Nguyen, S.L.; Vu, A.T.; Giuliano, A.E.; Hoon, D.S. Estrogen receptor and HER2/neu status affect epigenetic differences of tumor-related genes in primary breast tumors. Breast Cancer Res. 2008, 10, R46. [CrossRef]

28. Roll, J.D.; Rivenbark, A.G.; Jones, W.D.; Coleman, W.B. DNMT3b overexpression contributes to a hypermethylator phenotype in human breast cancer cell lines. Mol. Cancer 2008, 7, 15. [CrossRef]

29. Saji, S.; Kawakami, M.; Hayashi, S.; Yoshida, N.; Hirose, M.; Horiguchi, S.; Itoh, A.; Funata, N.; Schreiber, S.L.; Yoshida, M.; et al. Significance of HDAC6 regulation via estrogen signaling for cell motility and prognosis in estrogen receptor-positive breast cancer. Oncogene 2005, 24, 4531-4539. [CrossRef]

30. Chang, M. Tamoxifen resistance in breast cancer. Biomol. Ther. 2012, 20, 256-267. [CrossRef]

31. Jones, P.L.; Veenstra, G.J.; Wade, P.A.; Vermaak, D.; Kass, S.U.; Landsberger, N.; Strouboulis, J.; Wolffe, A.P. Methylated DNA and MeCP2 recruit histone deacetylase to repress transcription. Nat. Genet. 1998, 19, 187-191. [CrossRef] [PubMed]

32. Richon, V. Cancer biology: Mechanism of antitumour action of vorinostat (suberoylanilide hydroxamic acid), a novel histone deacetylase inhibitor. Br. J. Cancer 2006, 95, S2. [CrossRef]

33. Damaskos, C.; Garmpis, N.; Valsami, S.; Kontos, M.; Spartalis, E.; Kalampokas, T.; Kalampokas, E.; Athanasiou, A.; Moris, D.; Daskalopoulou, A.; et al. Histone Deacetylase Inhibitors: An Attractive Therapeutic Strategy Against Breast Cancer. Anticancer Res. 2017, 37, 35-46. [CrossRef] [PubMed]

34. Kondo, Y. Epigenetic cross-talk between DNA methylation and histone modifications in human cancers. Yonsei Med. J. 2009, 50, 455-463. [CrossRef] [PubMed]

35. Jeltsch, A.; Broche, J.; Bashtrykov, P. Molecular Processes Connecting DNA Methylation Patterns with DNA Methyltransferases and Histone Modifications in Mammalian Genomes. Genes 2018, 9, 566. [CrossRef] [PubMed]

36. Sharma, D.; Blum, J.; Yang, X.; Beaulieu, N.; Macleod, A.R.; Davidson, N.E. Release of methyl CpG binding proteins and histone deacetylase 1 from the Estrogen receptor alpha (ER) promoter upon reactivation in ER-negative human breast cancer cells. Mol. Endocrinol. 2005, 19, 1740-1751. [CrossRef] [PubMed]

37. Pryzbylkowski, P.; Obajimi, O.; Keen, J.C. Trichostatin A and 5 Aza-2' deoxycytidine decrease estrogen receptor mRNA stability in ER positive MCF7 cells through modulation of HuR. Breast Cancer Res. Treat. 2008, 111, 15-25. [CrossRef]

38. Billam, M.; Sobolewski, M.D.; Davidson, N.E. Effects of a novel DNA methyltransferase inhibitor zebularine on human breast cancer cells. Breast Cancer Res. Treat. 2010, 120, 581-592. [CrossRef]

39. Chen, M.Y.; Liao, W.S.; Lu, Z.; Bornmann, W.G.; Hennessey, V.; Washington, M.N.; Rosner, G.L.; Yu, Y.; Ahmed, A.A.; Bast, R.C., Jr. Decitabine and suberoylanilide hydroxamic acid (SAHA) inhibit growth of ovarian cancer cell lines and xenografts while inducing expression of imprinted tumor suppressor genes, apoptosis, G2/M arrest, and autophagy. Cancer 2011, 117, 4424-4438. [CrossRef] 
40. Henderson, C.; Mizzau, M.; Paroni, G.; Maestro, R.; Schneider, C.; Brancolini, C. Role of caspases, Bid, and p53 in the apoptotic response triggered by histone deacetylase inhibitors trichostatin-A (TSA) and suberoylanilide hydroxamic acid (SAHA). J. Biol. Chem. 2003, 278, 12579-12589. [CrossRef] [PubMed]

41. Kumagai, T.; Wakimoto, N.; Yin, D.; Gery, S.; Kawamata, N.; Takai, N.; Komatsu, N.; Chumakov, A.; Imai, Y.; Koeffler, H.P. Histone deacetylase inhibitor, suberoylanilide hydroxamic acid (Vorinostat, SAHA) profoundly inhibits the growth of human pancreatic cancer cells. Int. J. Cancer 2007, 121, 656-665. [CrossRef] [PubMed]

42. El-Awady, R.A.; Saleh, E.M.; Dahm-Daphi, J. Targeting DNA double-strand break repair: Is it the right way for sensitizing cells to 5-fluorouracil? Anticancer Drugs 2010, 21, 277-287. [CrossRef] [PubMed]

43. El-Awady, R.A.; Saleh, E.M.; Ezz, M.; Elsayed, A.M. Interaction of celecoxib with different anti-cancer drugs is antagonistic in breast but not in other cancer cells. Toxicol. Appl. Pharmacol. 2011, 255, 271-286. [CrossRef] [PubMed]

44. El-Awady, R.A.; Semreen, M.H.; Saber-Ayad, M.M.; Cyprian, F.; Menon, V.; Al-Tel, T.H. Modulation of DNA damage response and induction of apoptosis mediates synergism between doxorubicin and a new imidazopyridine derivative in breast and lung cancer cells. DNA Repair 2016, 37, 1-11. [CrossRef] [PubMed]

45. Saleh, E.M.; El-awady, R.A.; Eissa, N.A.; Abdel-Rahman, W.M. Antagonism between curcumin and the topoisomerase II inhibitor etoposide: A study of DNA damage, cell cycle regulation and death pathways. Cancer Biol. Ther. 2012, 13, 1058-1071. [CrossRef] [PubMed]

46. Saleh, E.M.; El-Awady, R.A.; Abdel Alim, M.A.; Abdel Wahab, A.H. Altered expression of proliferation-inducing and proliferation-inhibiting genes might contribute to acquired doxorubicin resistance in breast cancer cells. Cell Biochem. Biophys. 2009, 55, 95-105. [CrossRef] [PubMed]

47. Wlodkowic, D.; Skommer, J.; Darzynkiewicz, Z. Flow cytometry-based apoptosis detection. Methods Mol. Biol. 2009, 559, 19-32. [CrossRef]

(C) 2018 by the authors. Licensee MDPI, Basel, Switzerland. This article is an open access article distributed under the terms and conditions of the Creative Commons Attribution (CC BY) license (http:/ / creativecommons.org/licenses/by/4.0/). 